\title{
Evaluation of effects of metritis management in a complex dairy herd health management program
}

\author{
M. A. Krogh ${ }^{1}$ and C. Enevoldsen \\ Department of Large Animal Sciences, Faculty of Health and Medical Sciences, University of Copenhagen, \\ Grønnegårdsvej 2, DK-1870 Frederiksberg C, Denmark
}

\section{ABSTRACT}

Evaluating the effects of all interventions in a dairy herd, including the effects of various herd health management programs (HHMP), is highly relevant. A traditional randomized controlled trial is the gold standard but is likely practically impossible or prohibitively expensive to use for a general evaluation of a HHMP. Generalizability may also be poor because of the dynamics of the production contexts. In this study, we demonstrate an approach for evaluating the effects of an HHMP in the field, specifying an intervention theory for an ongoing HHMP in the context of the Danish dairy industry. As an example, we suggest one coherent analytical approach for studying the possible effects on milk production of systematic postpartum examinations of vaginal discharge, which is supposed to improve detection and treatment of metritis or endometritis. This routine is one component of the HHMP. The data consisted of 121 herds and 76,953 lactations over a 15 -yr period. For parity group 1 , the negative effects of metritis (despite treatment) on 305-d milk production after a normal calving were reduced by $116 \mathrm{~kg}$ of energy-corrected milk after enrollment in the HHMP. For parity group 2 and parity group $>2$, enrollment in the HHMP resulted in a $129-\mathrm{kg}$ and an 80-kg energy-corrected milk yield increase in milk production, respectively. The results indicate that effects of the HHMP existed, which were mediated through improved metritis detection. This study demonstrates the importance of a clear-cut intervention theory, although even with a theory, the research question can be too herd and context specific. In such a case, a withinherd randomized controlled trial study design seems to be the only way to achieve a valid result for a given herd, and acquiring valid results from an observational multi-herd study will be very difficult.

Key words: metritis, herd health management, evaluation

Received March 28, 2012

Accepted September 27, 2013.

${ }^{1}$ Corresponding author: mok@raskedyr.dk

\section{INTRODUCTION}

Because of the apparently decreasing profit margin in dairy production, an increasing need exists to evaluate the effects of services offered to and used by the producer. Evaluations obviously must include the effects of herd health management programs (HHMP), including very commonly applied disease treatment regimens. It is straightforward to use a randomized controlled trial (RCT) approach to assess the effects at the animal level of changing from one drug to another, and $\mathrm{RCT}$ is the gold standard method in medicine (Krogstrup, 2011). However, an HHMP is usually composed of multiple procedures, dynamic performance measurements, and feedback mechanisms, and the herd will usually be the unit of interest. An RCT with herds as the study population becomes very complicated due to random allocation of HHMP, farmer compliance to the RCT, and exchange of information between farmers and advisors. Often, economic compensation is required to make farmers comply with the trial protocol to compensate for time, effort, negative effects of treatment, and so on. Similar to evaluation in public management (Krogstrup, 2011), the RCT approach can be practically impossible or prohibitively expensive to use for a general evaluation of an HHMP, and generalizability may be poor because of the dynamics of the production context (Verstegen et al., 1995).

The estimation of effects of an HHMP is analogous to providing evidence of effects of various programs (interventions) in social systems, which is a large discipline per se. The evaluation of an HHMP can be categorized as a wild problem. A wild problem is characterized by a vague definition, lack of an optimal solution, unclear causal mechanisms, and interaction between context and mechanisms. According to Krogstrup (2011), one prerequisite to providing evidence of causal effects in such complicated social systems is to specify an intervention theory. Based on this theory, we may be able to deduce which components and paths within the intervention program can be used to evaluate causal effects of one or more maybe minor components of the intervention. 
The purposes of this study were to demonstrate one approach to specifying an intervention theory for an ongoing HHMP in the context of the Danish dairy industry concerning intervention against postpartum metritis. Based upon the developed intervention theory, we present a corresponding data analysis for estimating possible causal effects given this intervention theory. We selected postpartum metritis because it is an important health disorder in dairy cattle, causing large production losses (Østergaard and Gröhn, 1999; Goshen and Shpigel, 2006). Hence, interest exists in detecting this condition early to intervene effectively.

\section{MATERIALS AND METHODS}

\section{Study Context}

During the 1990s, several Danish cattle veterinarians were inspired to implement the key components of an Israeli HHMP described by Nir-Markusfeld (1993). One key component of the Danish adaptation of the Israeli program was the local veterinarian's systematic clinical examination of well-defined groups of cows with an expected high probability of health problems. The clinical examination was performed by a local veterinarian every 7 or $14 \mathrm{~d}$. Fresh cows between 5 and 21 DIM and cows about $10 \mathrm{wk}$ before expected calving were always examined. Quite detailed guides and manuals for the clinical work in the herds were available, such as guides for scoring body condition or vaginal discharge. Every fresh cow was examined gynecologically by the veterinarian. The examination was performed to estimate the degree of metritis based on an evaluation of the vaginal discharge. The results were given on an ordinal scale from 0 (no metritis) to 9 (severe metritis). However, qualitative studies showed that the use of scores, examination methods, and treatment protocols differed among veterinarians (Kristensen et al., 2008; Lastein et al., 2009). Records of diagnoses and medical treatments of disease symptoms were collected in all herds by means of a limited number of diagnosis codes. The use of these codes was highly herd specific, as described in detail by Vaarst et al. (2002) in a study related to mastitis treatment, but we expect that similar mechanisms occurred in the case of other diseases.

\section{The Intervention Theory}

Because we can regard the dairy HHMP described above as a wild problem with unclear causal mechanisms, and interaction between context and mechanisms, the evaluation of the effects of the program is very complicated. One option for evaluating an HHMP may be to study the possible causal effects of a single component of the HHMP for which we can specify rather simple mechanisms. In this work, we chose to study the possible effects on milk production of systematic postpartum examinations of vaginal discharge, which is supposed to improve detection of metritis or endometritis. Because these diagnoses are indistinguishable in our setting, we have designated them collectively as metritis in this paper. We based the study on the following expectations concerning metritis diagnosis and treatments (MDT), and we specifically focus on the relationship between metritis treatment and milk yield because milk yield is a very important performance indicator that can be defined objectively. The relationship between MDT and subsequent milk production has been estimated several times [e.g., Fourichon et al. (1999), Bar and Ezra (2005), and Goshen and Shpigel (2006)]. In our context, it is not sufficient to make a simple comparison of the relationship between milk and MDT before and after the start of the intervention program (HHMP) because the threshold for detections inevitably will change over time. That is, the number of undetected MDT cases in the nontreated group may be reduced. We must also take into account that numerous studies have found clear relationships between stillbirth, dystocia, twin calving, retained placenta, and metritis (Deluyker et al., 1991; Correa et al., 1993; Emanuelson et al., 1993). Metritis with or without previous calving complications is likely to constitute different entities with different effects on milk yield and recovery rates from medical treatment (Pugh et al., 1994). We also assume that the way the risk factors for metritis are recorded did not change when the examinations began. The prevalences of the risk factors are, however, likely to change with the beginning of examinations because the dairy producer may take action (hopefully) to prevent metritis by reducing the occurrence of these major determinants of metritis.

In this study, neither the ordinal scale of the metritis score nor the specific threshold for treatment was used for the following reasons: first, the results from the examinations for metritis were not available before the initiation of the HHMP. Second, the examination method changed from farmer-based perception of disease to the veterinarians' systematic examinations of all cows. In diagnostic test terminology, this change will mean that at the time point of initiation of the HHMP, the sensitivity and specificity of metritis detection changed, most likely toward a higher sensitivity and lower specificity. How much it changed is impossible to estimate but is expected to be dependent on the farmer's previous conception of metritis (herd specific) and the veterinarian's conception of metritis and at- 
titude toward the HHMP (Lastein et al., 2009). Finally, work by Lastein et al. (2009) suggests that the score values of metritis in some instances will be modified if the veterinarian believes that the cow deserves treatment for particular reasons (preferential treatment).

Given the study context and intervention theory described above, we could reduce the wild problem to a statistically tractable problem as formulated with the following specific objective: We want to demonstrate an approach to evaluate the effect on milk production of early postpartum gynecological examinations and associated medical treatments given the context of the Danish HHMP and the mechanisms suggested above. The evaluation is based on a statistical model that estimates the effects on milk yield of time of program initiation, occurrence of calving complications, and MDT.

\section{Data Collection}

In December 2009, herds were selected from the Veterinary Production and Consultancy database (Enevoldsen, 2006) based on the following criteria: (1) the herd should have at least 2 yr of registrations of routinely conducted clinical examinations, (2) the herd should be enrolled in the milk recording program with the standard number of annual test dates (at least 11), (3) data should be available 2 yr before the initiation of the herd health program and 2 yr after the initiation of the program, and (4) within this 4-yr period, a minimum of $75 \%$ of the calvings should be Danish Holsteins. Based on these criteria, 121 herds and 76,953 calvings were selected.

\section{Data Preparation}

On the 11 annual test dates, the amount of milk (in $\mathrm{kg}$ ), the fat percentage, and the protein percentage were recorded. Based on these values, the test-day ECM yield was calculated using the equation of Tyrrell and Reid (1965):

$$
\begin{gathered}
\mathrm{kg} \text { of } \mathrm{ECM}=[\mathrm{kg} \text { of milk } \times(383 \times \text { fat percentage } \\
+242 \times \text { protein percentage }+780.8)] / 3,140 .
\end{gathered}
$$

The ECM on a given test day was subsequently adjusted with a lactation curve model. The lactation curve model is based on a straight line from calving to 60 DIM and a subsequent straight line decrease in production throughout lactation. This lactation curve model has been applied by Bennedsgaard et al. (2003) and Nielsen et al. (2009) and was run separately for each herd and each parity group. The lactation curve model is given in Equation 1:

$$
\begin{aligned}
& \operatorname{ECM}_{i j}=\beta_{00}+\beta_{1} \mathrm{DIMun}_{0} 0_{i j}+\beta_{2} \mathrm{DIM}_{6 i j}+\varepsilon_{i j}, \\
& \text { where } \beta_{00}=\beta_{0}+\mu_{0 j}, \beta_{1}=\beta_{1}+\mu_{1 j}, \text { and } \beta_{2}=\beta_{2}+\mu_{2 j} ; \\
& \left(\begin{array}{l}
\mu_{0 j} \\
\mu_{1 j} \\
\mu_{2 j}
\end{array}\right) \sim \mathrm{N}\left(0, \Omega_{\mu}\right): \Omega_{\mu}=\left(\begin{array}{lll}
\sigma_{\mu 0}^{2} & \\
\sigma_{\mu 01}^{2} & \sigma_{\mu 1}^{2} \\
\sigma_{\mu 02}^{2} & \sigma_{\mu 12}^{2} & \sigma_{\mu 2}^{2}
\end{array}\right) ; \\
& \varepsilon_{i j} \sim N\left(0, \sigma_{\varepsilon}^{2}\right),
\end{aligned}
$$

where $\mathrm{ECM}_{i j}$ was the kilograms of ECM on the $i$ th test day of the $j$ th cow; DIMun60 $0_{i j}$ was the $i$ th DIM of the $j$ th cow for DIM 1 to 60 (for DIM larger than 60, DIM60 takes the value 0$)$; DIM60 $i j$ was the $i$ th $($ DIM -60$) / 245$ of the $j$ th cow for 60 to 305 DIM (for values less than 60 DIM, DIM60 takes the value 0); $\beta_{0}$ can be separated into an overall mean $\left(\beta_{00}\right)$ that represents the average milk yield at 60 DIM for that herd and parity, and a contribution from the individual cows $\left(\mu_{0 j}\right) ; \beta_{1}$ and $\beta_{2}$ were the fixed linear regression coefficients of DIMun60 $0_{i j}$ and DIM60 $0_{i j}$; $\mu_{1 j}$ was the random linear regression coefficient of DIMun60 $0_{i j} ; \mu_{2 j}$ was the random linear regression coefficient of DIM $60_{i j}$; and $\varepsilon_{i j}$ was the random residual component. $\Omega_{\mu}$ is the variance-covariance matrix related to $\mu_{0 j}, \mu_{1 j}$, and $\mu_{2 j}$. The variances related to $\mu_{0 j}, \mu_{1 j}$, and $\mu_{2 j}$ are $\sigma_{\mu 0}, \sigma_{\mu 1}$, and $\sigma_{\mu 2}$ and the covariances between $\mu_{0 j}$, $\mu_{1 j}$, and $\mu_{2 j}$ are $\sigma_{\mu 01}, \sigma_{\mu 12}$ and $\sigma_{\mu 02}$.

Based on model 1, the predicted milk production at 10, 60, and 305 DIM was estimated for each cow. These 3 predictions allowed us to estimate the total 305-d milk production in lactation (MPL) as the area under the curve. The advantage of this approach is that herdspecific culling decisions are accounted for because MPL is calculated even though the lactation is terminated early after calving. Consequently, MPL is not a measure of the actual milk production but a prediction of the milk production if the cow remained in the herd throughout lactation. That is, this approach makes milk production from individual cows comparable.

In Denmark, it is mandatory to record the sex of the calf and the condition of the calf/calves after calving using an 8-point categorical scale. In essence, 2 values describe a living calf and 6 describe variations of a dead calf. Calving ease can be recorded but is not mandatory, using a 5-point categorical scale in which 1 is an unassisted calving and 5 is a caesarean section. Based on this information, a new variable was created to describe dystocia, named DYS. In total, $81.2 \%$ of the calvings were normal with a living calf, and $9.6 \%$ of the calvings resulted in calving with a dead calf.

Cows that had a recorded diagnosis code of metritis with medical treatment within the first $21 \mathrm{~d}$ postpartum 
were classified as cows with MDT. All cows diagnosed with metritis were also treated.

\section{Statistical Models}

A multilevel random intercept model was specified for parity groups 1,2 , and $>2$ separately to take into account that the calving outcome of dystocia most likely is a different entity in the parity groups. Separate models are needed for each parity group because of the lack of variance homogeneity over parity groups. The dependent variable was MPL. The independent variables were year of calving (YR), season as quarter of the year of calving (SEAS), a variable to describe whether the calving occurred when the herd was enrolled in the HHMP, the dystocia variable (DYS), and MDT. All 2-way interactions and the 3-way interactions between HHMP, DYS, and MDT were included. The baseline model is given in Equation 2:

$$
\begin{gathered}
\mathrm{MPL}_{j k}=\beta_{0}+\beta_{1} \mathrm{SEAS}_{j k}+\beta_{2} \mathrm{YR}_{j k}+\beta_{3} \mathrm{MDT}_{j k} \\
+\beta_{4} \mathrm{DYS}_{j k}+\beta_{5} \mathrm{HHMP}_{j k}+\beta_{6} \mathrm{MDT}_{j k} \times \mathrm{HHMP}_{j k} \\
+\beta_{7} \mathrm{MDT}_{j k} \times \mathrm{DYS}_{j k}+\beta_{8} \mathrm{DYS}_{j k} \times \mathrm{HHMP}_{j k} \\
+\beta_{9} \mathrm{MDT} \times \mathrm{HHMP}_{j k} \times \mathrm{DYS}_{j k}+\varepsilon_{j k},
\end{gathered}
$$

where $\beta_{0}=\beta_{00}+\mu_{0 k}$ and $\mu_{0 k} \sim N\left(0, \sigma_{0 k}\right)$ and $\varepsilon_{j k} \sim$ $N\left(0, \sigma_{j k}\right), \mathrm{MPL}_{j k}$ was the predicted $305-\mathrm{d} \mathrm{kg}$ of ECM produced in the lactation of the $j$ th cow of the $k$ th herd; $\mathrm{SEAS}_{j k}$ was season of calving for the $j$ th cow of the $k$ th herd (4 categories); $\mathrm{YR}_{j k}$ was the year of the calving for the $j$ th cow of the $k$ th herd ( 15 categories); $\mathrm{MDT}_{j k}$ was treatment of metritis at the calving of the $j$ th cow in the $k$ th herd (2 categories); $\mathrm{DYS}_{j k}$ was dystocia at the calving of the $j$ th cow in the $k$ th herd (6 categories); $\mathrm{HHMP}_{j k}$ was whether the calving of the $j$ th cow in the $k$ th herd was included in the herd health program $(2$ categories $) ; \mathrm{MDT}_{j k} \times \mathrm{HHMP}_{j k} \times \mathrm{DYS}_{j k}, \mathrm{MDT}_{j k} \times$ $\mathrm{HHMP}_{j k}, \mathrm{HHMP}_{j k} \times \mathrm{DYS}_{j k}$, and $\mathrm{MDT}_{j k} \times \mathrm{DYS}_{j k}$ were the 3 -way and 2 -way interactions between the main effects; $\beta_{0}$ can be separated into an overall mean $\left(\beta_{00}\right)$ that represents the average MPL across herds and a contribution from the individual herds $\left(\mu_{0 k}\right) ; \beta_{1}$ to $\beta_{9}$ were the fixed class coefficients of SEAS ${ }_{j k}, \mathrm{YR}_{j k}, \mathrm{MDT}_{j k}$, $\mathrm{DYS}_{j k}, \mathrm{HHMP}_{j k}, \mathrm{MDT}_{j k} \times \mathrm{HHMP}_{j k}, \mathrm{MDT}_{j k} \times \mathrm{DYS}_{j k}$, $\mathrm{DYS}_{j k} \times \mathrm{HHMP}_{j k}$, and $\mathrm{MDT}_{j k} \times \mathrm{HHMP}_{j k} \times \mathrm{DYS}_{j k}$, respectively; and $\varepsilon_{j k}$ was the random residual component.

The analyses were performed with the MIXED procedure (Littell et al., 2006) in SAS (SAS Institute Inc., Cary, NC) using maximum likelihood estimation. The deviance test was used to test for fixed effects in the model. The baseline model was reduced with backward elimination $(P>0.2)$. Model assumptions were investigated by histograms, quantile-quantile plots, and residuals versus predicted values. Variance homogeneity across herds was evaluated by boxplots of the conditional studentized residuals.

\section{RESULTS}

\section{Descriptive Statistics}

The frequency of MDT is given in Table 1 to verify the assumption that the detection and treatment threshold for metritis would be lower after enrollment in the HHMP (see intervention theory above). Table 1 also shows the distribution of MDT within parity groups, and before and after enrollment in the HHMP.

Table 1 shows that normal calvings with a living calf before enrollment in the HHMP had a probability of MDT that was approximately half the probability of MDT at calvings with a dead calf. The probability of MDT approximately doubled after enrollment in the HHMP for both calving with a dead calf and having a normal calving, except for calving with a dead calf in parity group 2 .

Figure 1 shows the number of calvings included in the analysis for each year. It is obvious that the years 1995 to 1997 were entirely estimated from calvings that had not been included in the herd health program and that the years 2007 to 2009 almost entirely were from cows that had been enrolled in the herd health program. Note that each herd will contribute to 4 calendar years in this study. Figure 1 shows that a large proportion of new herds were enrolled in the program in 2005.

Table 2 gives key characteristics (unadjusted) of what happened in these 121 herds when comparing the 2-yr period before enrollment in the HHMP with the 2 -yr follow-up period. In $25 \%$ of the herds, the number of calvings increased by more than 38 calvings every 2 yr. Thus, there was an increase in herd size in a substantial proportion of herds during the study period. Because the average number of calvings per year before enrollment in the HHMP was around 150, it is unlikely that improved reproduction alone can account for this increase. Table 2 also shows that the average difference in days to first insemination hardly changed.

For half of the herds, the milk production increased by more than $200 \mathrm{~kg}$ of ECM, whereas $25 \%$ of herds had no increase in average milk production in lactation. Although this description is crude and to some extent may be related to differences in herd demographics as with distribution of parity groups, it indicates that most herds experienced an increase in MPL over a 4-yr period.

As expected, the odds of receiving an MDT after versus before enrollment indicated a substantially higher probability of receiving an MDT in almost every herd 


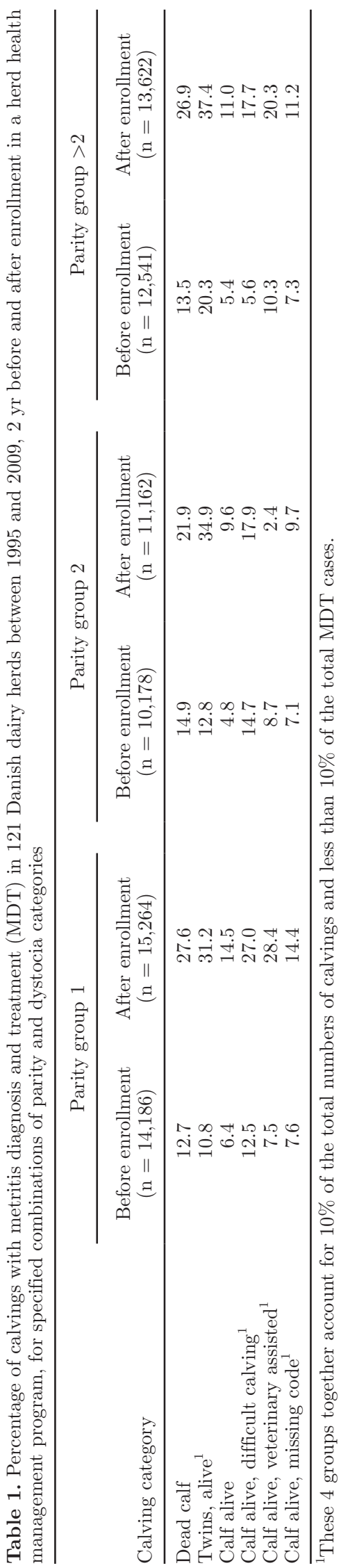

(lower quartile is 1.5). This finding supports the expectations concerning increased detection intensity.

\section{Statistical Analyses}

In the analyses of all 3 parity groups, the effects of YR and SEAS were highly significant $(P<0.001)$. For parity group 1 , the 3 -way interaction of MDT $\times$ HHMP $\times$ DYS was significant $(P=0.0015)$. Hence, the baseline model could not be reduced. For parity group 2 , the 3 -way interaction MDT $\times \operatorname{HHMP} \times \operatorname{DYS}(P=$ $0.29)$ and MDT $\times \operatorname{HHMP}(P=0.43)$ were removed. The 2-way interactions MDT $\times$ DYS and HHMP $\times$ DYS were both significant $(P=0.008$ and $P=0.045$, respectively). The final reduced model for parity group 2 then contained the interactions MDT $\times$ DYS and HHMP $\times$ DYS, their main effects, and YR and SEAS. For the parity group $>2$, the 3 -way interaction MDT $\times$ HHMP $\times$ DYS $(P=0.94)$ and the interactions HHMP $\times \operatorname{MDT}(P=0.94)$ and HHMP $\times$ DYS $(P=0.85)$ were removed from the model. The final reduced model for parity group $>2$ consisted of the interaction DYS $\times$ MDT $(P<0.0001)$, the main effects of the interaction, the main effect of HHMP $(P=0.03)$, and SEAS and YR. The model control indicated variance homogeneity across herds and the specified visual evaluations for the model assumptions were acceptable.

Table 3 shows parameter estimates for the 3 final models. For the dystocia variable, only the categories of normal calving and dead calf are shown because these 2 categories accounted for more than $90 \%$ of the observations.

Figure 2 illustrates the parity-specific effect of YR adjusted for enrollment in the HHMP, SEAS, and DYS and indicates a clear increase in milk production from 1998 to 2004 . However, it is important to note that the herds that contributed to year 2000 were not the same as those that contributed to year 2005 .

Table 4 shows least squares means differences for selected effects. Again, only effects related to the DYS categories of normal calving and dead calf are shown. For parity group 1 with a normal calving, MDT cows produced $192 \mathrm{~kg}$ of ECM less than a non-MDT cow if the cows were not enrolled in the HHMP. This difference was reduced to $69 \mathrm{~kg}$ of ECM in the HMMP. This means that cows diagnosed and treated for metritis had a production loss despite treatment. Non-MDT parity group 1 cows produced the same amount of milk $(7 \mathrm{~kg}$ of ECM difference) regardless of whether the cows were enrolled in the HHMP or not. The MDT cows produced $116 \mathrm{~kg}$ of ECM more if the treatment took place after enrollment in the HHMP. All differences were nonsignificant $(P>0.11)$ for parity group 1 cows that calved with a dead calf. 
Table 2. Herd-level differences in key characteristics of herd demographics, production, and metritis treatment status in 121 Danish dairy herds comparing 2 yr before and $2 \mathrm{yr}$ after enrollment in the herd health management program

\begin{tabular}{lccc}
\hline Characteristic & $\begin{array}{c}\text { Lower } \\
\text { quartile }\end{array}$ & Median & $\begin{array}{c}\text { Upper } \\
\text { quartile }\end{array}$ \\
\hline Difference in number of calvings & -1 & 13 & 38 \\
Difference in average 305-d ECM production $(\mathrm{kg})$ & -16 & 214 & 532 \\
Difference in days to first insemination & -2 & 1 & 4 \\
Odds of receiving a metritis treatment after versus before & 1.5 & 2.6 & 5.6 \\
enrollment in the herd health management program & & & \\
\hline
\end{tabular}

Among cows from parity group 2 that had a normal calving, MDT cows produced $91 \mathrm{~kg}$ of ECM less than non-MDT cows. Cows enrolled in the HHMP that had a normal calving produced $127 \mathrm{~kg}$ of ECM more than cows not enrolled. For parity group 2 cows that had a dead calf, MDT cows produced $348 \mathrm{~kg}$ of ECM less than non-MDT cows. No effect of being enrolled in the HHMP was observed if the calving resulted in a dead calf.

For cows in parity group $>2$ with a normal calving, MDT cows produced $247 \mathrm{~kg}$ of ECM less than nonMDT cows. A calving that resulted in a dead calf in parity group $>2$ cows with MDT produced $194 \mathrm{~kg}$ of ECM less than non-MDT cows. In parity group $>2$, the effect of being enrolled in the HHMP was $80 \mathrm{~kg}$ of ECM.

\section{DISCUSSION}

The highly significant 3-way interaction among HHMP, DYS, and MDT in parity group 1 shows that the across-herds effect of the HHMP depended not only on the DYS occurrence but also on whether the cows had MDT. In parity group 1 with cows having a normal calving, the negative effect of MDT was $192 \mathrm{~kg}$ of ECM before enrollment in the HHMP and $69 \mathrm{~kg}$ of ECM after enrollment. The negative effect of $192 \mathrm{~kg}$ of ECM can be considered a baseline milk loss of a case of MDT. This loss associated with a MDT case was then reduced after enrollment in HHMP. However, as hypothesized above, it is very likely that MDT cases before and after enrollment do not describe the same clinical condition. Because of a reduced detection threshold, MDT cases before enrollment in the HHMP probably were more severe with a larger milk loss than MDT cases after enrollment in the HHMP. Thus, it is possible that what we found here was merely a dilution effect arising from inclusion of cows that had experienced minor or no milk production loss, regardless of treatment in the MDT group.

We know from Table 1 that the average probability of MDT before enrollment in the HHMP was $6.4 \%$ and $14.5 \%$ after enrollment in parity group 1 having a normal calving. Based on these figures, the total milk

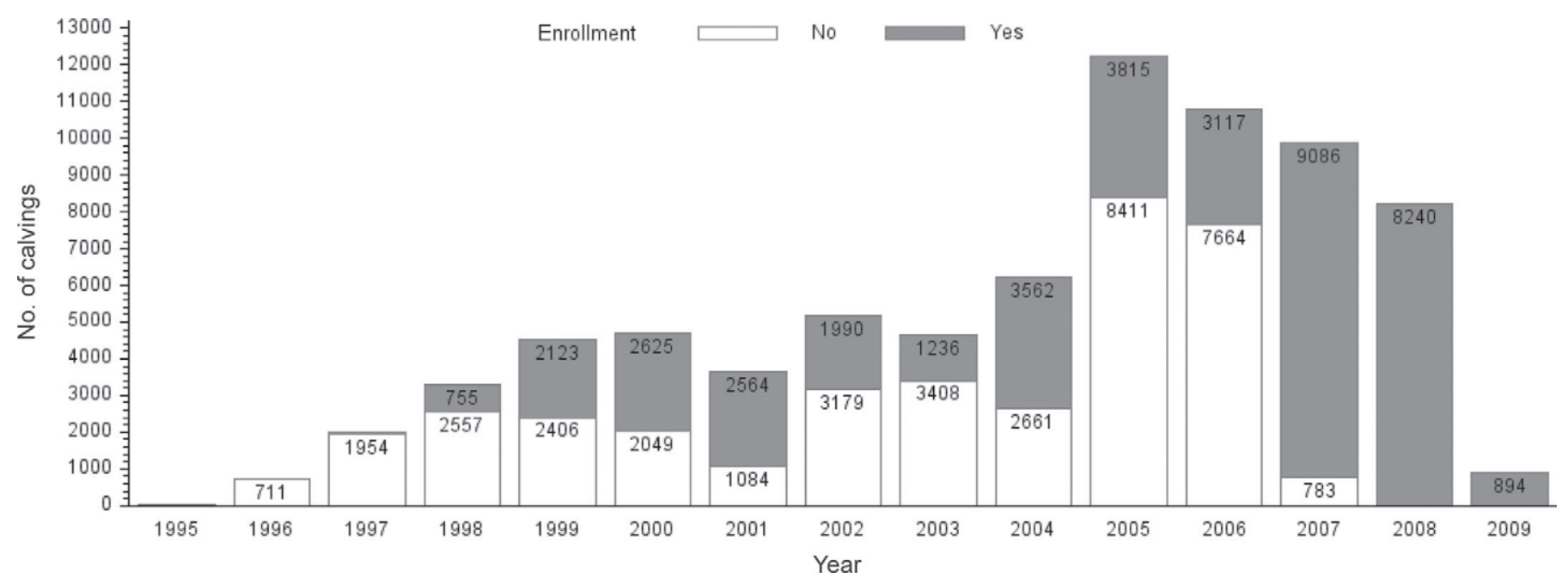

Figure 1. Distribution of the 76,953 calvings from the 121 Danish dairy herds over the study period. Each herd contributed to 4 calendar years: $2 \mathrm{yr}$ before enrollment in the herd health management program and $2 \mathrm{yr}$ after enrollment. For each calendar year, the number of calvings not enrolled and enrolled are given. 


\begin{tabular}{|c|c|c|c|c|c|c|c|c|c|c|c|c|c|c|}
\hline \multirow[b]{2}{*}{ Variable } & \multicolumn{5}{|c|}{ Category } & \multicolumn{3}{|c|}{ Parity group 1} & \multicolumn{3}{|c|}{ Parity group 2} & \multicolumn{3}{|c|}{ Parity group $>2$} \\
\hline & YR & HHMP & SEAS & DYS & MDT & Estimate & $\mathrm{SE}^{2}$ & $P$-value & Estimate & $\mathrm{SE}$ & $P$-value & Estimate & $\mathrm{SE}$ & $P$-value \\
\hline Intercept & & - & & & - & 8,829 & 116 & $<0.0001$ & 9,851 & 165 & $<0.0001$ & 10,082 & 170 & $<0.0001$ \\
\hline SEAS & & - & 1 & & - & -156 & 20 & $<0.0001$ & -21 & 30 & 0.47 & -85 & 3 & 0.0047 \\
\hline SEAS & & - & 2 & & - & -230 & 20 & $<0.0001$ & -169 & 29 & $<0.0001$ & -259 & 29 & $<0.0001$ \\
\hline SEAS & & - & 3 & & - & -153 & 18 & $<0.0001$ & -280 & 28 & $<0.0001$ & -363 & 27 & $<0.0001$ \\
\hline SEAS & & - & 4 & & - & $\mathrm{REF}^{3}$ & - & - & REF & - & - & REF & - & - \\
\hline YR & 1995 & & & & & $-1,539$ & 369 & $<0.0001$ & $-2,453$ & 552 & $<0.0001$ & $-1,610$ & 675 & 0.017 \\
\hline YR & 1996 & - & & & - & $-1,878$ & 162 & $<0.0001$ & $-2,112$ & 240 & $<0.0001$ & $-2,060$ & 237 & $<0.0001$ \\
\hline YR & 1997 & - & & & - & $-1,536$ & 139 & $<0.0001$ & $-1,777$ & 205 & $<0.0001$ & $-1,698$ & 208 & $<0.0001$ \\
\hline YR & 1998 & - & & & - & $-1,530$ & 129 & $<0.0001$ & $-1,810$ & 189 & $<0.0001$ & $-1,686$ & 193 & $<0.0001$ \\
\hline YR & 1999 & - & & & - & $-1,471$ & 118 & $<0.0001$ & $-1,788$ & 174 & $<0.0001$ & $-1,496$ & 177 & $<0.0001$ \\
\hline YR & 2000 & - & & & - & $-1,221$ & 111 & $<0.0001$ & $-1,437$ & 164 & $<0.0001$ & $-1,303$ & 168 & $<0.0001$ \\
\hline YR & 2001 & - & & & - & -994 & 103 & $<0.0001$ & $-1,217$ & 155 & $<0.0001$ & $-1,206$ & 158 & $<0.0001$ \\
\hline YR & 2002 & & & & & -728 & 92 & $<0.0001$ & -789 & 141 & $<0.0001$ & -870 & 143 & $<0.0001$ \\
\hline YR & 2003 & - & & & - & -412 & 90 & $<0.0001$ & -558 & 138 & $<0.0001$ & -593 & 140 & $<0.0001$ \\
\hline YR & 2004 & - & & & - & -393 & 77 & $<0.0001$ & -353 & 122 & 0.0038 & -286 & 123 & 0.020 \\
\hline YR & 2005 & - & & & - & -268 & 71 & 0.0002 & -302 & 114 & 0.0080 & -301 & 115 & 0.0092 \\
\hline YR & 2006 & - & & & - & -161 & 68 & 0.017 & -231 & 110 & 0.035 & -203 & 111 & 0.068 \\
\hline YR & 2007 & - & & & - & -228 & 63 & 0.0003 & -359 & 104 & 0.0005 & -281 & 105 & 0.0076 \\
\hline YR & 2008 & & & & & -143 & 63 & 0.023 & -280 & 104 & 0.0068 & -235 & 105 & 0.025 \\
\hline YR & 2009 & - & & & - & REF & - & - & REF & - & - & REF & - & - \\
\hline DYS & & - & & Calf dead & - & -216 & 53 & $<0.0001$ & -587 & 88 & $<.0001$ & 80 & 38 & 0.037 \\
\hline DYS & & - & & Normal calving & - & -4 & 46 & 0.92 & 135 & 69 & 0.053 & 0 & - & - \\
\hline HHMP & & Enrolled & & & - & -141 & 72 & 0.049 & -160 & 99 & 0.11 & 80 & 38 & 0.037 \\
\hline HHMP & & Not enrolled & & & - & REF & - & - & REF & - & - & REF & - & - \\
\hline HHMP $\times$ DYS & & Enrolled & & Calf dead & - & 81 & 80 & 0.31 & 141 & 124 & 0.26 & & & $\mathrm{NS}^{4}$ \\
\hline HHMP $\times$ DYS & & Enrolled & & Normal calving & - & 133 & 70 & 0.058 & 286 & 99 & 0.0037 & & & NS \\
\hline HHMP $\times$ DYS & & Not enrolled & & Calf dead & - & REF & - & - & REF & - & - & & & NS \\
\hline HHMP $\times$ DYS & & Not enrolled & & Normal calving & - & REF & - & - & REF & - & - & & & NS \\
\hline MDT & & - & & & $\mathrm{MDT}+$ & -308 & 136 & 0.024 & -519 & 159 & 0.0011 & -179 & 156 & 0.25 \\
\hline MDT & & - & & & MDT - & REF & - & - & REF & - & - & REF & - & - \\
\hline DYS $\times$ MDT & & - & & Calf dead & $\mathrm{MDT}+$ & 314 & 158 & 0.047 & 171 & 189 & 0.36 & 15 & 180 & 0.93 \\
\hline DYS $\times$ MDT & & - & & Calf dead & MDT - & REF & - & - & REF & - & - & REF & - & - \\
\hline $\mathrm{DYS} \times \mathrm{MDT}$ & & - & & Normal calving & $\mathrm{MDT}+$ & 116 & 143 & 0.42 & 428 & 164 & 0.0093 & -67 & 160 & 0.67 \\
\hline $\mathrm{DYS} \times \mathrm{MDT}$ & & - & & Normal calving & MDT - & REF & - & - & REF & - & - & REF & - & - \\
\hline $\mathrm{HHMP} \times \mathrm{MDT}$ & & Enrolled & & & $\mathrm{MDT}+$ & 291 & 195 & 0.14 & & & NS & & & NS \\
\hline $\mathrm{HHMP} \times \mathrm{MDT}$ & & Enrolled & & & MDT - & REF & - & - & & & NS & & & NS \\
\hline $\mathrm{HHMP} \times \mathrm{MDT}$ & & Not enrolled & & & $\mathrm{MDT}+$ & REF & - & - & & & NS & & & NS \\
\hline $\mathrm{HHMP} \times \mathrm{MDT}$ & & Not enrolled & & & MDT - & REF & - & - & & & NS & & & NS \\
\hline $\mathrm{HHMP} \times \mathrm{DYS} \times \mathrm{MDT}$ & & Enrolled & & Calf dead & $\mathrm{MDT}+$ & -378 & 219 & 0.084 & & & NS & & & NS \\
\hline $\mathrm{HHMP} \times \mathrm{DYS} \times \mathrm{MDT}$ & & Enrolled & & Calf dead & MDT - & REF & - & - & & & NS & & & NS \\
\hline $\mathrm{HHMP} \times \mathrm{DYS} \times \mathrm{MDT}$ & & Enrolled & & Normal calving & $\mathrm{MDT}+$ & -168 & 202 & 0.41 & & & NS & & & NS \\
\hline HHMP $\times$ DYS $\times$ MDT & & Enrolled & & Normal calving & MDT - & REF & - & - & & & NS & & & NS \\
\hline $\mathrm{HHMP} \times \mathrm{DYS} \times \mathrm{MDT}$ & & Not enrolled & & Calf dead & MDT + & REF & - & - & & & NS & & & NS \\
\hline $\mathrm{HHMP} \times \mathrm{DYS} \times \mathrm{MDT}$ & & Not enrolled & & Calf dead & MDT - & REF & - & - & & & NS & & & NS \\
\hline HHMP $\times$ DYS $\times$ MDT & & Not enrolled & & Normal calving & $\mathrm{MDT}+$ & REF & - & - & & & NS & & & NS \\
\hline $\mathrm{HHMP} \times \mathrm{DYS} \times \mathrm{MDT}$ & & Not enrolled & & Normal calving & MDT - & REF & - & - & & & NS & & & NS \\
\hline
\end{tabular}

The baseline model given in model 2 was analyzed for each parity group (parity 1,2, and $>2$ ) and reduced by backward elimination. The dependent variable was the 305-d milk production in lactation (ECM). The models included year (YR), season (SEAS), enrollment in the herd health management program (HHMP), metritis diagnosis and treatment (MDT), dystocia (DYS), and interactions between enrollment in the HHMP, MDT, and DYS.

${ }^{2} \mathrm{SE}=\mathrm{SE}$ of the estimate.

${ }^{4} \mathrm{NS}$ = variable removed from the model as nonsignificant during model reduction. 


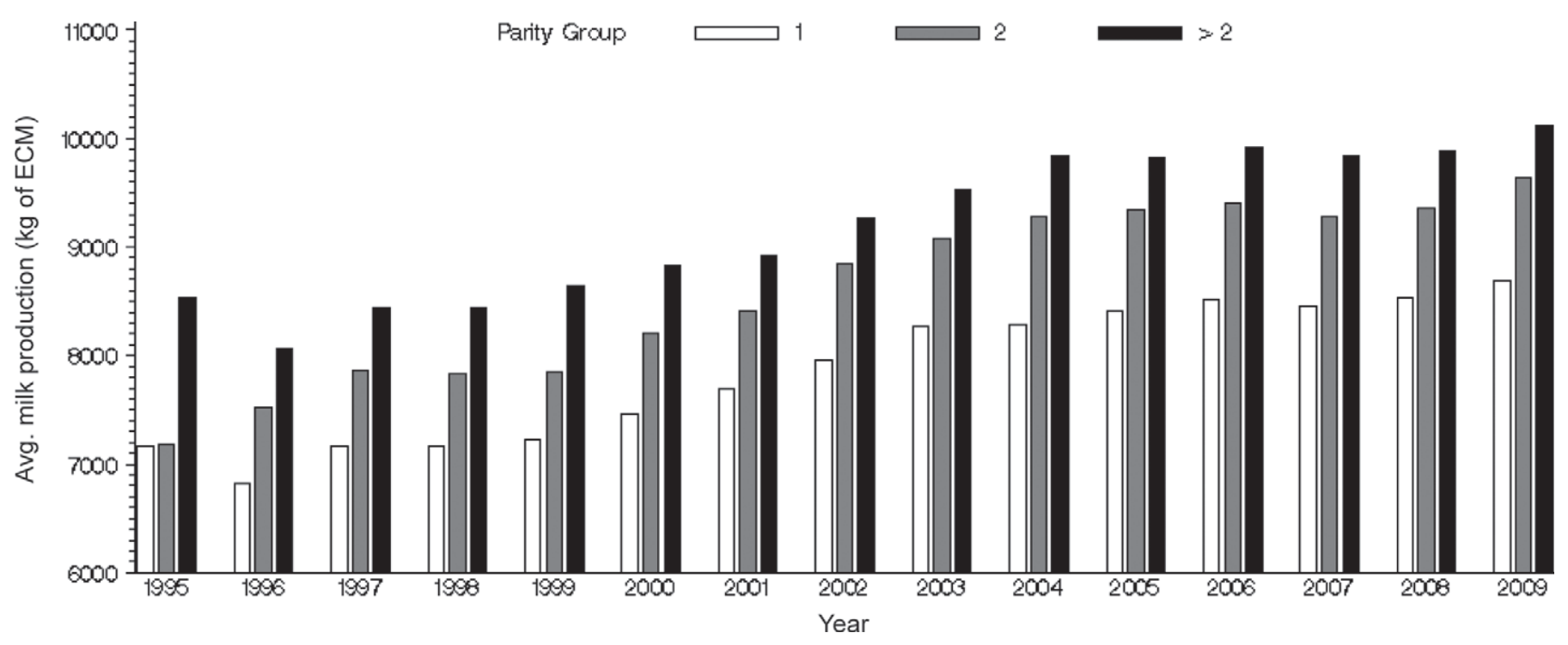

Figure 2. Parity-specific effect of year of calving derived from the 3 analyses of 76,953 calvings from 121 Danish dairy herds. The estimates are adjusted for enrollment in the herd health management program, dystocia, and metritis treatment. Avg. = average.

production loss in an average herd can be calculated before and after enrollment in the HHMP. Such a calculation shows that the total milk production loss related to MDT was reduced by $17 \%$ after enrollment, indicating that non-MDT cases existed before enrollment and that these cases benefitted from being diagnosed and treated after enrollment in the HHMP. Looking at the non-MDT cases before and after enrollment in the
HHMP, we found no difference in milk production $(7 \mathrm{~kg}$ of ECM). A difference was expected because the population of cows before enrollment included non-MDT cases that could have experienced some milk production loss, whereas the population after enrollment did not include this group of cows. We expect that the milk production loss of these additionally diagnosed and treated cows was somewhat less than for cows treated

Table 4. Least squares means differences in 305-d ECM production for selected categories of the herd health management program (HHMP), dystocia, and metritis treatment ${ }^{1}$

\begin{tabular}{|c|c|c|c|}
\hline HMMP & Dystocia & Metritis treatment $^{2}$ & $\begin{array}{c}\text { Effect } \\
(\mathrm{kg} \text { of } \mathrm{ECM})\end{array}$ \\
\hline \multicolumn{4}{|l|}{ Parity group 1} \\
\hline Not enrolled & Normal calving & Undiagnosed vs. diagnosed & $-192 * * *$ \\
\hline Not enrolled vs. enrolled & Normal calving & Untreated & $-7, \mathrm{NS}$ \\
\hline Not enrolled vs. enrolled & Normal calving & Treated & $116^{*}$ \\
\hline Not enrolled & Dead calf & Undiagnosed vs. diagnosed & 7, NS \\
\hline Not enrolled vs. enrolled & Dead calf & Treated & $-146, \mathrm{NS}$ \\
\hline \multicolumn{4}{|l|}{ Parity group 2} \\
\hline \multirow{3}{*}{ Not enrolled vs. enrolled } & Normal calving & Undiagnosed vs. diagnosed & $-91^{*}$ \\
\hline & Normal calving & & $127^{* * *}$ \\
\hline & Dead calf & Undiagnosed vs. diagnosed & $-348^{* *}$ \\
\hline \multirow{2}{*}{$\begin{array}{l}\text { Not enrolled vs. enrolled } \\
\text { Parity group }>2\end{array}$} & Dead calf & & $-18, \mathrm{NS}$ \\
\hline & Normal calving & Undiagnosed vs. diagnosed & $-247^{* * *}$ \\
\hline
\end{tabular}

${ }^{1}$ The estimated differences are for each comparison highlighted in bold. The other categories are fixed. The differences should be interpreted as the change in ECM moving from not enrolled to enrolled or from undiagnosed to diagnosed. Empty cells mean that the category of the variable did not influence the estimated difference.

${ }^{2}$ All cows diagnosed for metritis were also treated for the condition.

${ }^{*} P<0.05 ; * *<0.01 ; * * P<0.001$. 
before enrollment in the HHMP. Because the magnitude of the production loss was smaller, it is likely that the approximately $8 \%$ (14.5\% after enrollment vs. $6.4 \%$ before enrollment) of cows additionally diagnosed and treated after enrollment in the HHMP was too small to be detected when diluted in the $>80 \%$ normal cows. As for the MDT cases, a positive effect of enrollment was observed in the HHMP (116 kg of ECM), which corresponded nicely with the difference between MDT cases and non-MDT cases before and after enrollment in the HHMP. The possible explanation for this effect has been discussed above.

If the calving resulted in a dead calf in parity group 1 , none of the effects were significant. The probability of being an MDT case was $12.7 \%$ before enrollment in the HHMP among calvings that resulted in a dead calf. After enrollment, the corresponding probability was 27.6\%. Possible reasons for the lack of effects despite this increased detection intensity could be that farmers were aware of problems with heifers that experienced a calving with a dead calf. The consequence would be that the proportion of non-MDT cows that had experienced a milk production loss was small compared with normal calvings with a living calf. In addition, there could be other diseases of the genital tract (injuries in the vulva or vagina) that caused pain or infections that were treated and recorded. The treatment of these other infections could have some preventive effect on the probability of subsequent metritis. Hence, it is possible that a cow had a case of metritis that was never recorded. Routine examinations of cows will tend to focus on metritis detection, and the probability of having a diseased cow recorded as metritis will be greater despite the possible co-occurrence of other diseases.

In parity group 2, the negative effect of MDT was $91 \mathrm{~kg}$ of ECM if the calving was normal, regardless of enrollment in HHMP. This effect is about half of the corresponding negative effect for parity group 1 cows. The positive effect of being enrolled in the HHMP was $127 \mathrm{~kg}$ of ECM, regardless of MDT if calving was normal. This finding can be interpreted as prevention of a production loss of $127 \mathrm{~kg}$ of ECM if the parity group 2 cows were enrolled in the HHMP and the calving was normal. Because the interaction between DYS and HHMP was significant, the effect of the HHMP was essentially modified by DYS, which provides support for our hypothesis that the effect of the HHMP on 305-d ECM is related to the gynecological examination and metritis detection.

If the calving of a parity group 2 cow resulted in a dead calf, the negative effect was $348 \mathrm{~kg}$ of ECM, regardless of enrollment in the HHMP. This effect was much greater than for parity group 1 cows, which could indicate that the mechanisms that led to a dead calf in parity group 2 were quite different from the mechanisms that led to a dead calf in parity group 1 . Dystocia caused by problems with the relative size of the cow and the calf is highly associated with heifers. The probability of MDT before enrollment in the HHMP was $14.9 \%$ and $21.9 \%$ after enrollment if the parity group 2 cow had a dead calf. This increase was rather modest compared with the other parity groups (Table 1) and suggests that the type of cow with MDT before and after enrollment in the HHMP was similar or that treatments had virtually no effect.

Parity group $>2$ cows with MDT after a normal calving produced $247 \mathrm{~kg}$ of ECM less than non-MDT cows, regardless of enrollment in the HHMP. This milk production loss is in the same range as for parity groups 1 and 2, especially if the milk production loss is seen relative to the entire production of the parity groups. After a calving that resulted in a dead calf, the milk loss was $192 \mathrm{~kg}$ of ECM, which was substantially smaller than for parity group 2. A possible reason could be that other diseases such as parturient paresis were the cause of the dead calf. These diseases may not cause pain or infections to the same extent as diseases in younger cows. For parity group $>2$, a positive main effect of enrollment in the HHMP (80 kg of ECM) was observed, but this could not be related to MDT.

The milk loss associated with MDT as identified in the current study can be compared with the work of Goshen and Shpigel (2006). In an RCT setting, they found that milk production losses from metritis could be totally avoided by treatment. Actually, an increased milk production in 305-d lactation was observed for the treated group. They also estimated a $300-$ to $500-\mathrm{kg}$ milk (not ECM as in the current study) production loss associated with untreated metritis. That value represents a substantially larger effect than what we found, but because we did not have animals diagnosed and left untreated in our study, this true milk loss resulting from metritis cannot be estimated here. However, we still identified an approximately 200-kg ECM production loss related to the diagnosed and treated cases of metritis. A possible explanation could be differences in treatment protocols. A common metritis treatment in Denmark is one-fifth the amount of oxytetracycline used in Israel. In addition, some Danish veterinarians treat mild metritis cases with prostaglandins alone. The effect of this treatment at this stage of lactation is debatable (e.g., Archbald et al., 1990). The consequence of metritis on milk production has also been estimated by Østergaard and Gröhn (1999). They found no effect of metritis on first-parity cows and a $239-\mathrm{kg}$ ECM production loss in the first $182 \mathrm{~d}$ of lactation in secondand-older parities compared with healthy cows. In our study, we found a substantial effect of MDT on 305-d 
milk production in parity group 1 in contrast to the findings of Østergaard and Gröhn (1999), whereas their estimate of second-and-older parities is comparable to our findings. One possible reason could be that their results were based on 3 research dairy herds that may have differed from ours with respect to environment and management.

Our presentation of the intervention program (the HHMP), its context, our intervention theory, and the discussion of our results demonstrate that evaluation of an HHMP in dairy herds is complex. Despite a relatively clear intervention theory about the relationship between DYS and MDT before and after enrollment in the HHMP, the problem of evaluation of this minor part of the HHMP still remains a wild problem, or at least complicated. In terms of the causal mechanisms described in the introduction, we believe we had a good understanding of the mechanisms and outcome. However, it is also clear that we did not have sufficient information about the context (herds) to fully interpret the results. This raises the question of whether or not it is possible to evaluate a complex HHMP in a multiherd observational study. The answer will be that it is possible if the effects of the HHMP are strictly founded in biological or pathological mechanisms that manifest themselves equally across herds and cows. If the contexts are very important and many management factors exist that can influence the outcome of the results, then multi-herd analysis will most likely be of limited relevance. If context is important, a within-herd RCT study design seems to be the only way to achieve a valid result for a given herd.

This study does not address the question whether an intensified HHMP is profitable or not. The prerequisite for financial benefits related to an HHMP in the individual herd obviously is some positive effects on production, fertility, or costs, which could be estimated with a statistical model based on the principles suggested in this study. A concept for an economic analysis at herd level was presented by Enevoldsen et al. (1995) and this concept is now commercialized (http://www. simherd.com). At the national level, nonfinancial benefits of an HHMP may exist (despite poor evidence of effects on herd-level productivity), because it may serve as a tool to monitor and document health status in the herds for surrounding community and consumers.

\section{REFERENCES}

Archbald, L. F., T. Tran, P. G. A. Thomas, and S. K. Lyle. 1990. Apparent failure of prostaglandin $\mathrm{F} 2 \mathrm{a}$ to improve the reproductive efficiency of postpartum dairy cows that had experienced dystocia and/or retained fetal membranes. Theriogenology 34:1025-1034.

Bar, D., and S. Ezra. 2005. Effect of common calving diseases on milk production in high yielding dairy cows. Isr. J. Vet. Med. 60:106-111.

Bennedsgaard, T. W., C. Enevoldsen, S. M. Thamsborg, and M. Vaarst. 2003. Effect of mastitis treatment and somatic cell counts on milk yield in Danish organic dairy cows. J. Dairy Sci. 86:31743183.

Correa, M. T., H. Erb, and J. Scarlett. 1993. Path analysis for seven postpartum disorders of Holstein cows. J. Dairy Sci. 76:13051312.

Deluyker, H. A., J. M. Gay, L. D. Weaver, and A. S. Azari. 1991 Change of milk yield with clinical diseases for a high producing dairy herd. J. Dairy Sci. 74:436-445.

Emanuelson, U., P. A. Oltenacu, and Y. T. Gröhn. 1993. Nonlinear mixed model analyses of five production disorders of dairy cattle. J. Dairy Sci. 76:2765-2772.

Enevoldsen, C. 2006. Epidemiological tool for herd diagnosis. Page 376-383 in Proceedings of XXIV World Buiatrics Congress, Nice, France. H. Navetat and F. Schelcher, ed. World Association for Buiatrics.

Enevoldsen, C., J. T. Sørensen, I. Thysen, C. Guard, and Y. T. Gröhn. 1995. A diagnostic and prognostic tool for epidemiologic and economic analysis of dairy herd health management. J. Dairy Sci. 78:947-961.

Fourichon, C., H. Seegers, N. Bareille, and F. Beaudeau. 1999. Effects of disease on milk production in the dairy cow: A review. Prev. Vet. Med. 41:1-35. http://dx.doi.org/10.1016/S0167-5877(99)00035-5.

Goshen, T., and N. Y. Shpigel. 2006. Evaluation of intrauterine antibiotic treatment of clinical metritis and retained fetal membranes in dairy cows. Theriogenology 66:2210-2218.

Kristensen, E., D. B. Nielsen, L. N. Jensen, M. Vaarst, and C. Enevoldsen. 2008. A mixed methods inquiry into the validity of data Acta Vet. Scand. 50:30.

Krogstrup, H. K. 2011. Kampen om evidens. Resultatmåling, effektevaluering og evidens. [In Danish]. Hans Reitzel Forlag, Copenhagen, Denmark.

Lastein, D. B., M. Vaarst, and C. Enevoldsen. 2009. Veterinary decision making in relation to metritis-A qualitative approach to understand the background for variation and bias in veterinary medical records. Acta Vet. Scand. 51:36 http://dx.doi. org/10.1186/1751-0147-51-36.

Littell, R. C., G. A. Milliken, W. W. Stroup, R. D. Wolfinger, and O. Schabenberger. 2006. SAS for Mixed Models. 2nd ed. SAS Inst. Inc. Cary, NC.

Nielsen, S. S., M. A. Krogh, and C. Enevoldsen. 2009. Time to the occurrence of a decline in milk production in cows with various paratuberculosis antibody profiles. J. Dairy Sci. 92:149-155.

Nir-Markusfeld, O. 2003. What are production diseases, and how do we manage them? Acta Vet. Scand. 98(Suppl.):21-32.

Østergaard, S., and Y. T. Gröhn. 1999. Effects of diseases on test day milk yield and body weight of dairy cows from Danish research herds. J. Dairy Sci. 82:1188-1201.

Pugh, D. G., M. Q. Lowder, and J. G. W. Wenzel. 1994. Retrospective analysis of the management of 78 cases of postpartum metritis in the cow. Theriogenology 42:455-463.

Tyrrell, H. F., and J. T. Reid. 1965. Prediction of the energy values of cow's milk. J. Dairy Sci. 48:1215-1223.

Vaarst, M., B. Paarup-Laursen, H. Houe, C. Fossing, and H. J. Andersen. 2002. Farmers' choice of medical treatment of mastitis in Danish dairy herds based on qualitative research interviews. J. Dairy Sci. 85:992-1001.

Verstegen, J. A. A. M., R. B. M. Huirne, A. A. Dijkhuizen, and J. P. C. Kleijnen. 1995. Economic value of management information systems in agriculture: A review of evaluation approaches. Comput. Electron. Agric. 13:273-288. 